\title{
Atık Mukavva, Alçı, Pomza, Perlit, Vermikülit ve Zeolit ile Yapılan Kompozitlerin Yangın Direncinin Araştırılması
}

\author{
Hanifi BİNİCi ${ }^{* 1}$ \\ ${ }^{1}$ Kahramanmaraș Sütçü Imam Üniversitesi,Mühendislik Mimarlık Fakültesi, \\ Inş̧aat Mühendisliği Bölümü, Kahramanmaraş
}

Geliş tarihi: 29.11 .2015

Kabul tarihi: 22.04 .2016

Özet

Bu çalışmada, atık mukavva, alçı, pomza, perlit, vermikülit ve zeolit ile yapılan kompozitlerin yangın direnci ASTM E 160-50'ye göre belirlenmiştir. Numunelerin birim hacim ağırlıkları, su emme oranları ile 1Sı iletim katsayısı ve ultra ses geçirgenlik katsayısı bulunmuştur. Atık mukavva, alçı, pomza, perlit, vermikülit ve zeolit ile yapılan kompozitlerin 1sı iletim ve ultra ses geçirgenlik katsayısı oldukça düşük bulunmuştur. Test sonuçlarına göre en uzun yanma süresi üçlü karışımlardan elde edilmiştir. En kısa sürede yanan örnekler ise ikili karışımlardan özellikle alçı ve perlit katkılı olan örneklerdir. Sonuç olarak, atık mukavvanın alçı, pomza, perlit, vermikülit ve zeolitin ikili ve üçlü karışımlarıyla elde edilen kompozitlerin yangına yeterli direnç gösterdiği ve yanmayı geciktirdiği anlaşılmıştır.

Anahtar Kelimeler: Yangın, Atık mukavva, Alçı, Pomza, Perlit, Vermikülit, Zeolit

\section{The Investigation of Fire Resistance of Composites Made with Waste Cardboard, Gypsum, Pumice, Perlite, Vermiculite and Zeolite}

\begin{abstract}
In this paper, fire resistance of the composite made with waste cardboard, gypsum, pumice, perlite, vermiculite and zeolite was determined according to ASTM E 160-50. Unit weight, water absorption rate, ultra sonic penetration, heat conductivity and permeability coefficient of the samples was found. Thermal conductivity, ultra-sound transmission coefficient of composites made with zeolite, waste cardboard, plaster, pumice, perlite and vermiculite is very low. According to the test results the longest burn time were obtained from the triple mixes. Fire resistance of gypsum and perlite binary mixtures was lowest. As a result, it was found that the ternary and binary mixture made with waste cardboard, gypsum, pumice, perlite, vermiculite and the zeolite showed enough resistance to fire and by delaying burning.
\end{abstract}

Keywords: Fire,Waste cardboard, Gypsum, Pumice, Perlite, Vermiculite, Zeolite

\footnotetext{
* Yazışmaların yapılacağı yazar: Hanifi Binici,Mühendislik Mimarlık Fakültesi, İnşaat Mühendisliği Bölümü, Kahramanmaraş. hbinici@ksu.edu.tr
} 


\section{GíRiş}

Ateş, insanlığın ilk çağlarından günümüze kadar ulaşan en önemli gelişmedir. İnsanoğlu 4000 yıldır ateşin bulunmasıyla beraber madenleri işleyip şekillendirmişler ve ateşi kontrol altında tutabildikleri sürece, kedilerine fayda sağlamışlardır. Ancak ateşin kontrol edilememesiyle de büyük yangınlar çıkmış ve şehir ölçeğindeki tahribatlara yol açmıştır [1-3]. Yangın, maddenin 1sı ve oksijenle birleşmesi sonucu oluşan yanma reaksiyonlarının neden olduğu doğal afettir. Yangınların oluştukları coğrafik alanda maddi hasarlara neden olmasından ziyade, orada yaşayan canlılar ve çevre dengesi üzerinde son derece olumsuz etkileri vardır.

Yangında sıcaklığın artması sonucu atomların titreşmesi ile atomlar arası bağları uzamaya başlar. $\mathrm{Bu}$ ise, bazı malzemelerin genleşme veya yumuşama-erime gibi değişimlere uğramasına neden olur. Zira yangın esnasında sıcaklığın artmasıyla ortaya çıkacak 1sı enerjisi, kristalli malzemelerden metal ve taşların; amorf yapılı olanlardan zeolit ve plastiklerin; karma yapılı olanlardan beton, seramik gibi malzemelerin içyapılarını etkilemektedir. Malzeme 1sınarak suyunu kaybettikçe ısıya bağlı olarak iç gerilmeler ve çatlaklar artar, dağılma etkisi yaratır [4]. Yanma, maddenin 1sı ve oksijenle birleşmesi sonucu oluşan kimyasal bir olaydır. Yanma olayının oluşabilmesi için madde, 1sı ve oksijenin bir arada olması gerekir. Yangınlar aşağıdaki sınıflar içerisinde tanımlanmaktadır.

A Sınıfı Yangınlar: Katı madde yangınlarıdır. Soğutma ve yanıcı maddenin uzaklaştırılması ile söndürülebilir.

B Sinıfı Yangınlar: Yanabilen sıvılar bu sinıfa girer. Soğutma ve boğma ile söndürülebilir.

C Sınıfi Yangınlar: Likit petrol gazı, hava gazı, hidrojen gibi yanabilen çeşitli gazların yanması ile oluşan yangınlardır.

D Sınıfi Yangınlar: Yanabilen hafif metallerin ve alaşımların yanmasıyla meydana gelen yangınlardır. Kuru kimyevi tozlar bu yangınları söndürmede kullanılırlar $[5,6]$.

\section{2. ÖNCEKİ ÇALIŞMALAR}

Bir malzeme yanmaya başladığında isı ortaya çıkarır ve malzemenin kendisi yanıcı ise bu malzemenin yanma sıcaklığı çok daha fazla olur [7]. İnsanların temel gereksinmelerinden biri de yangın güvenliğidir. Yangınlar insan hayatını ve can güvenliğini tehdit eden en önemli olaylardan biridir. Örneğin, dünyada kişi başına en çok enerji kullanan ilk üç ülke ABD, Kanada ve İngiltere'de istatistiklere göre yangın nedeni ile y1llık can kaybı, diğer ülkelere göre daha fazladır. Dolayısıyla teknoloji ilerledikçe ve endüstri alanında gelişmeler oldukça, ortaya çıkacak yangın olaylarında da artışlar olabilecektir. $\mathrm{Bu}$ nedenle hem ulusal boyutta hem de uluslararası boyutlarda var olan yangın güvenlik önlemlerini sürekli gözden geçirmek ve geliştirmek zorunludur [8]. Bu önlemlerin başında yangına daha dirençli malzeme üretimi gelmektedir. Özellikle yük taşıyıcı elemanların dışında diğer elemanların da yangın performansının dikkate alınması gerekir [4].

Yapı malzemelerinin yangına dirençli hale getirilmesi çalışmaları son yıllarda artış göstermiştir. Kuvars ve kumtaş1 yerine cüruf, perlit, sünger taşı gibi hafif agregalar kullanılmas1 yangın dayanım gücünü artıracaktır [9]. Dıș duvarların yanma hızının en ve boyca caddeye açık binalarda bir saat, bina ile kapalı caddeye yüzü olmayan binalarda ise en az iki saat olmas1 gerekmektedir. $\mathrm{Bu}$ sürenin sağlanması için, yapı elamanları arasında istenilen yanma süresine göre kalınlıkları belirlenmiş ateşe dayanıklı dolgu malzemeleri kullanılmaktadır. Örneğin bir saat süreli $800^{\circ} \mathrm{C}$ sıcaklık için; $5,3 \mathrm{~cm}$ kalınlıkta diatomit, $3,8 \mathrm{~cm}$ kalınlıkta vermikülit veya $4,3 \mathrm{~cm}$ kalınlıkta süngertaşı kullanılması yeterlidir. Dört saat süreli $1000^{\circ} \mathrm{C}$ sıcaklık için kalınlık olarak $12,5 \mathrm{~cm}$ perlit, $12 \mathrm{~cm}$ diatomit, $8 \mathrm{~cm}$ vermikülit, $9,2 \mathrm{~cm}$ süngertaşı veya taş veya cam yünü levhalar1 yeterlidir $[10,11]$.

Bu çalışmada atık mukavva, alçı, pomza, perlit, vermikülit ve zeolit ile yapılan kompozitlerin yangın direnci araştırılmıştır. Son yıllarda atıkların 
geri dönüşümü büyük önem kazanmıştır. Diğer yandan enerjiye olan ihtiyaç ta ortadadır. Ayrıca, hem yeterli yalıtım özelliği olan hem de yangına direnç gösteren malzemelerin araştırılması gereği vardır. $\mathrm{Bu}$ çalışma ile farklı mineral ve atık mukavvalardan uygun malzeme üretimi amaçlanmıştır.

\section{MATERYAL VE METOT}

\subsection{Materyal}

\subsubsection{Atık Mukavva}

Kağıdın ana hammaddesi odundur ve odun ise ya iğne yapraklı veya yapraklı ağaçlardan elde edilir. Kağıdın önemli bir hammaddesi de atık kağıttır. Atık kağıt, herhangi bir amaçla kullanıldıktan sonra ve atılan her türlü kağıt, karton ve mukavvalara denir. Hızlı nüfus artışı, konforlu hayat şartlarının gelişmesi, şehirleşme ve toplumların eğitim seviyesine ambalajlama sanayisinin gelişmemesi, kağıt-karton tüketimini artırmıştır [12]. Çalışmada kullanılan mukavvalar okuldaki atıklardan elde edilmiştir.

\subsubsection{Alçı}

Çalışmada toz şeklinde susuz alçı kullanılmıştır.

\subsubsection{Pomza}

Pomza boşluklu, volkanik olaylar sonucu oluşmuş, fiziksel ve kimyasal etkenlere karşı dayanıklı, cams1, volkanik bir kayaçtır. Yüksek oranda ve birbiriyle bağlantılı olmayan gözenekler içeren, $\% 50$ 'ye yakın nem suyu bulunduran ve toz haline getirildiğinde oldukça sert malzeme özelliği kazanan, ısı ve ses yalıtkanlığına, uygun basınç dayanımına sahip malzemedir. Pomzalar asidik veya bazik bileşimli olabilir [13]. Çalışmada kullanılan bazik pomza Osmaniye bölgesinden alınmıştır.

\subsubsection{Perlit}

Özellikle inşaat sektörü alanında önemli bir işleve sahip olan perlit, yapı malzemesi olarak kullanılan bir maddedir. İçeriğinde \%74 civarında $\mathrm{SiO}_{2} \% 15$ civarı bir oranda da $\mathrm{Al}_{2} \mathrm{O}_{3}$ bulunur [14]. Volkanik karakterli bir maddedir. Çok hafif olması en önemli özelliğidir. Yapı malzemesi olarak kendine alternatif olan madde ve karışımlara oranla \%50 oranında daha hafiftir. Çalışmada kullanılan genleştirilmiş perlit Niğde'den temin edilmiştir.

\subsubsection{Vermikülit}

Vermikulit, volkanik magma kaynaklarından elde edilen bir mineraldir. Yüksek 1sı ile işlenerek hacmi genişler, geçirgenliği artar ve hacim ağırlığı belirgin bir şekilde düşerek şekil değiştirir. Vermikülit, mikanın doğal aşınmasıyla oluşmuş magnezyum alümino silikat kil mineralidir. Bir kil minerali olan vermikülit Sivas-Yıldızeli'nden temin edilmiştir.

\subsubsection{Zeolit}

Zeolitler alüminyum ve silis içeren minerallerin çeşitli reaksiyonları sonucu oluşmuştur. Zeolitler kafes yapılarında alüminyum, silis ve oksijen, gözeneklerinde ise katyon ve su içeren mikro gözenekli kristal katılardır. Silis ve alüminyum atomları ortak oksijen atomu sayesinde birbirlerine tetrahedral olarak bağlanmışlardır $[15,16]$. Çalışmada kullanılan zeolit Manisa Gördes'ten temin edilmiştir. Zeolitler alkali ve toprak alkali elementlerin kristal yapıya sahip alüminyum silikatlarıdır [17]. Malzemelerin fiziksel özellikleri Çizelge 1'de ve kimyasal özellikleri Çizelge 2'de verilmiştir.

\subsection{Metot}

\subsubsection{Karıșımların Hazırlanması}

Öncelikle atık mukavva kağıtları 24 saat su içerisinde bekletilerek yumuşaması sağlanmıştır. Geçen süreden sonra yeteri kadar yumuşayan kağıt homojen duruma gelmesi ve hamur olması için mikser ile iyice karıştırılmıştır. Hamurun kıvamını ve fazla suyun alınması için mikro delikli bez süzekle suyu süzülmüştür. Hazır olan kağıt hamuruna Çizelge 3'de verilen oranlarda alçı, pomza, perlit, vermikülit ve zeolit (Şekil 1) katılarak farklı numuneler üretilmiştir. Boyutları 
Atık Mukavva, Alçı, Pomza, Perlit, Vermikülit ve Zeolit ile Yapılan Kompozitlerin Yangın Direncinin Araştırılması

16x16x4 cm örnekler hazırlanmış ve eşit miktarda sıkıştırılmıştır.

Çizelge 1. Malzemelerin fiziksel özellikleri

\begin{tabular}{|l|c|c|c|c|}
\hline \multirow{2}{*}{ Malzeme } & \multirow{2}{*}{$\begin{array}{c}\text { Birim hacim ağırlık } \\
\left(\mathrm{g} / \mathrm{cm}^{3}\right)\end{array}$} & \multirow{2}{*}{$\begin{array}{c}\text { Blaine } \\
\left(\mathrm{cm}^{2} / \mathrm{g}\right)\end{array}$} & $\begin{array}{c}\text { Elek analizi (\%) } \\
\text { üzerinde kalan }\end{array}$ & $\begin{array}{c}200 \mu \mathrm{m} \text { nolu elek üzerinde } \\
\text { kalan }\end{array}$ \\
\cline { 4 - 5 } & 2,24 & 2300 & 0,06 & 0,4 \\
\hline Alçı & 1,870 & 2500 & 0,05 & 0,6 \\
\hline Pomza & 0,678 & 2400 & 0,06 & 0,5 \\
\hline Perlit & 0,455 & 2600 & 0,03 & 0,7 \\
\hline Vermikülit & 2,183 & 2600 & 0,05 & 0,3 \\
\hline Zeolit & & &
\end{tabular}

Çizelge 2. Malzemelerin kimyasal içerikleri

\begin{tabular}{|l|c|c|c|c|c|c|c|}
\hline Malzeme & $\mathrm{SiO}_{2}$ & $\mathrm{Al}_{2} \mathrm{O}_{3}$ & $\mathrm{Fe}_{2} \mathrm{O}_{3}$ & $\mathrm{CaO}$ & $\mathrm{MgO}$ & $\mathrm{K}_{2} \mathrm{O}$ & $\mathrm{Na}_{2} \mathrm{O}$ \\
\hline Pomza & 43,6 & 14,8 & 12,6 & 9,8 & 8,9 & 1,1 & 1,6 \\
\hline Perlit & 67,1 & 11,8 & 3,7 & 1,2 & 0,2 & 1,5 & 0,8 \\
\hline Vermikulit & 44,3 & 12,4 & 13,5 & - & 12,2 & 1,4 & 1,1 \\
\hline Zeolit & 67,1 & 11,8 & 1,5 & 2,2 & 1,2 & 2,5 & 2,9 \\
\hline
\end{tabular}

Çizelge 3. Karışım miktarları (g)

\begin{tabular}{|c|c|c|c|c|c|c|c|}
\hline Numune no & Mukavva & Alç1 & Pomza & Perlit & Vermikulit & Zeolit & Su \\
\hline MA10 & 200 & 20 & - & - & - & - & 25 \\
\hline MA20 & 200 & 40 & - & - & - & - & 25 \\
\hline MAPO10 & 200 & - & 20 & - & - & - & 25 \\
\hline MAPO20 & 200 & - & 40 & - & - & - & 25 \\
\hline MPE10 & 200 & - & - & 20 & - & - & 25 \\
\hline MPE20 & 200 & - & - & 40 & - & - & 25 \\
\hline MV10 & 200 & - & - & - & 20 & - & 25 \\
\hline MV20 & 200 & - & - & - & 40 & - & 25 \\
\hline MZ10 & 200 & - & - & - & - & 20 & 25 \\
\hline MZ20 & 200 & & - & - & - & 40 & 25 \\
\hline MA10Z10 & 200 & 10 & - & - & - & 10 & 25 \\
\hline MA20Z20 & 200 & 20 & - & - & - & 20 & 25 \\
\hline MPO10V10 & 200 & - & 10 & - & 10 & - & 25 \\
\hline MPO20V20 & 200 & - & 20 & - & 20 & - & 25 \\
\hline MPE10V10 & 200 & - & - & 10 & 10 & - & 25 \\
\hline MPE20V20 & 200 & - & - & 20 & 20 & - & 25 \\
\hline MPO10V10Z10 & 200 & - & 10 & - & 10 & 10 & 30 \\
\hline MPO20V20Z20 & 200 & - & 20 & - & 20 & 20 & 30 \\
\hline MPE10V10Z10 & 200 & - & - & 10 & 10 & 10 & 30 \\
\hline MPE20V20Z20 & 200 & - & - & 20 & 20 & 20 & 30 \\
\hline
\end{tabular}




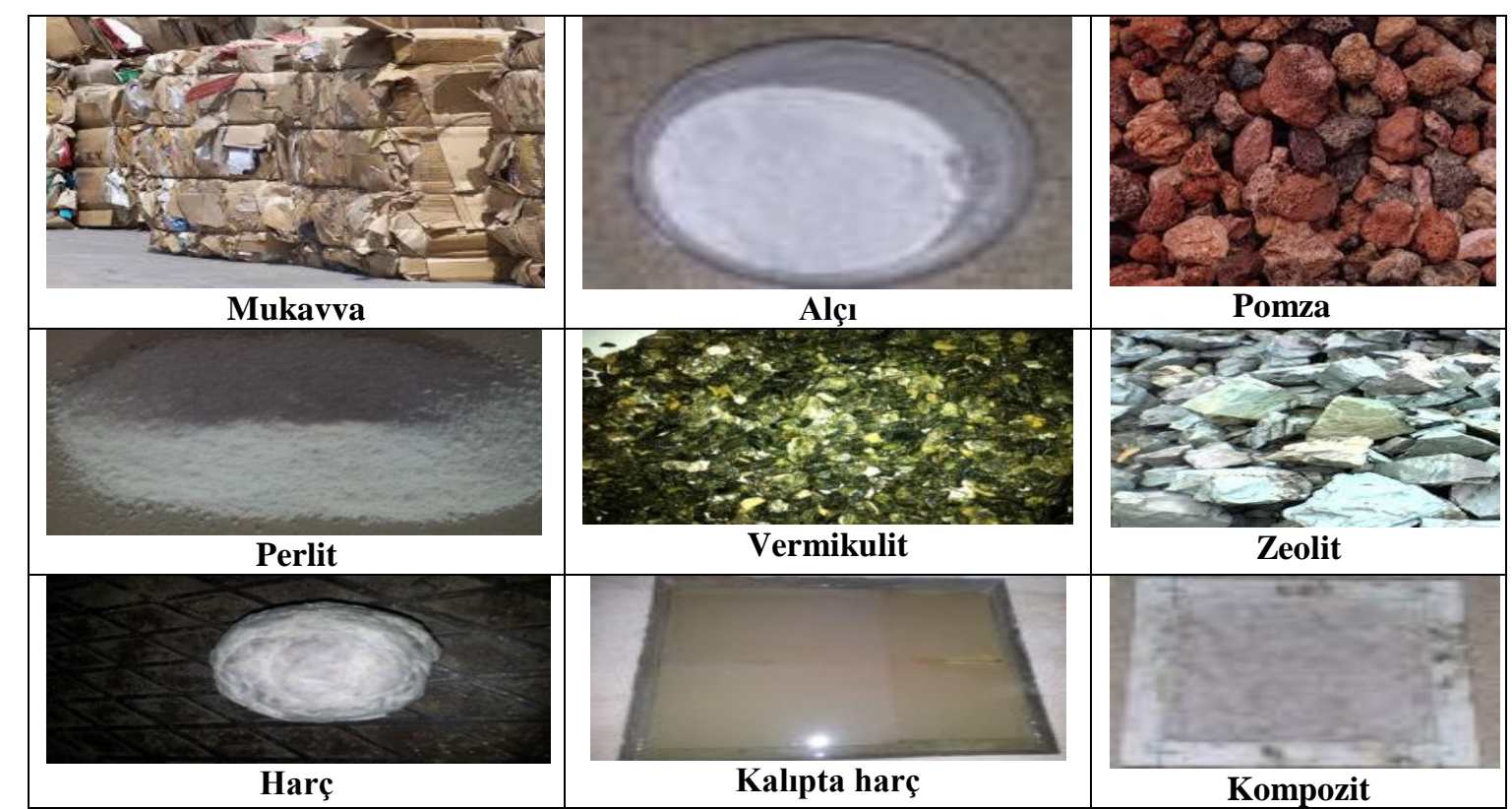

Şekil 1. Malzemeler ve üretilen kompozit

\subsubsection{Birim Hacim Ağırlığı ve Su Emme Oranı}

Üretilen örneklerin birim hacim ağırlıkları TS EN 2823'e göre ve su emme değerleri ise ASTM C 67-03'e göre bulunmuştur.

\subsubsection{Ultrasonik Ses Geçirgenliği ve Isı İletim Katsayısı}

Üretilen kompozitin 1s1 iletim katsayısı KEM marka QTM-500 model termal iletkenlik cihazı ile ölçülmüştür. Termal iletkenlik tayini deneyi ASTM C 1113-90'a göre yapılmıştır. Ultrasonik test cihazının kullanılmasıyla, malzeme içerisine gönderilen $\mathrm{P}$ ve $\mathrm{S}$ dalgalarının malzemenin bir yüzeyinden diğerine geçme süresi ölçülmekte, dalga hızı hesaplanmaktadır. Hesaplanan ses üstü dalga hızı ile malzemenin basınç dayanımı ve diğer özellikleri arasındaki ilişki yaklaşık olarak elde edilebilmektedir [18]. Numunenin bir yüzeyinden içeriye gönderilen ses üstü dalganın, bloğun diğer bir yüzeye ne kadar zamanda geçtiği ölçüldükten sonra, dalga hızı Eşitlik 1 ile hesaplanmaktadır:

$\mathrm{V}=(\mathrm{S} / \mathrm{t}) \cdot 10^{6}$
Burada; V = Dalga hızı $(\mathrm{km} / \mathrm{sn}), \mathrm{S}=$ Proplar arası mesafe (Malzeme bloğunun ses üstü dalga gönderilen yüzeyi ile dalganın alındığı yüzeyi arasındaki mesafe, kilometre), $\mathrm{t}=$ Dalganın gönderilmiş olduğu malzeme yüzeyinden, alındığ1 yüzeye kadar geçen zamandır (sn) [19]. Bu deneyde numunelerin karşılıklı olarak pürüzsüz yüzeyleri belirlenmiş ve pundit cihazının iki başlığı gres yağı ile yağlanmıştır. Yağlanan bu iki başlık numunenin yüzeyine karşılıklı gelecek şekilde sabitlenmiş ve sonra pundit cihazının okumaları yapılmıştır. Bu okumaların en küçük olanı alınmış ve yukarda verilen formül ile ultra ses hızı belirlenmiştir.

\subsubsection{Yangın Direncinin Belirlenmesi}

Üretilen malzemelerin yangın direnci kül firınında değişik sıcaklıklarda ve standarda göre yapılmıştır.

\subsubsection{Kül Fırınında Yakma İşlemi}

Kür işleminin ardından numuneler 50, 100, 150 ve $200^{\circ} \mathrm{C}$ sıcaklığa maruz bırakılmıştır. Numunelerin yüksek sıcaklıklarda ağırlık değişimleri belirlenmiştir. 


\subsubsection{ASTM E 160-50'e Göre Yangın Direnci}

Yanma deneylerinde ASTM-E 60-50'de belirtilen esaslara uyulmuştur. Test ve kontrol örnekleri yakma işleminden önce $27 \pm 2^{\circ} \mathrm{C}$ sicaklık ve $\% 30 \pm 5$ bağıl nem şartlarındaki iklimlendirme odasında $\% 7$ rutubete ulaşıncaya kadar bekletilmişlerdir. Kontrol örneklerinden bir kısmının rutubeti \%30 olarak muhafaza edilmiştir. Deneyde 24 adet örnek 12 katta kare prizma şeklinde dizilerek yakılmıştır. İşlem sırasında gaz basınc1 $0.5 \mathrm{~kg} / \mathrm{cm}^{2}$ sabit tutulmuştur. Ölçmeler alev kaynaklı, alev kaynaksız ve kor halinde olmak üzere üç aşamada yapılmıştır.

\section{BULGULAR VE TARTIŞMA}

\subsection{Birim Hacim Ağırlığı ve Su Emme Oranı}

Örneklerin birim hacim ağırlık ve su emme değerleri Çizelge 4'te verilmiştir.

Çizelge 4. Birim hacim ağırlık ve su emme değerleri

\begin{tabular}{|c|c|c|}
\hline Numuneler & $\begin{array}{c}\text { Birim hacim } \\
\text { ağırlık }\left(\mathrm{g} / \mathrm{cm}^{3}\right)\end{array}$ & $\begin{array}{c}\text { Su emme } \\
(\%)\end{array}$ \\
\hline MA10 & 1,48 & 78 \\
\hline MA20 & 1,51 & 71 \\
\hline MAPO10 & 1,69 & 81 \\
\hline MAPO20 & 2,15 & 76 \\
\hline MPE10 & 1,62 & 73 \\
\hline MPE20 & 1,68 & 69 \\
\hline MV10 & 1,79 & 74 \\
\hline MV20 & 1,35 & 45 \\
\hline MZ10 & 1,56 & 44 \\
\hline MZ20 & 2,88 & 47 \\
\hline MPO10V10 & 2,02 & 56 \\
\hline MPO20V20 & 1,25 & 41 \\
\hline MPE10V10 & 1,44 & 36 \\
\hline MPE20V20 & 1,64 & 30 \\
\hline MPO10V10Z10 & 1,45 & 43 \\
\hline MPO20V20Z20 & 1,52 & 35 \\
\hline MPE10V10Z10 & 1,57 & 45 \\
\hline MPE20V20Z20 & 1,63 & 32 \\
\hline
\end{tabular}

Pomza, perlit, vermikülit ve zeolit ile üretilen yalıtım malzemelerinin birim hacim ağırlıkları küçük iken su emme oranları daha yüksektir. Burada özellikle ikili karışımların göre üçlü karışımlarla üretilen kompozitlerin birim hacim ağırlıkları, daha büyük bulunmuştur. Pomza, perlit, vermikülit ve zeolitin üçlü karışımlarıyla üretilen kompozitlerde katkı oranı arttıça birim hacim ağırlık artarken su emme oranı azalmıştır. Alçı katkılı örneklerde ise katkı oranı arttıkça hem birim hacim ağırlık değerleri hem de su emme oranı artmıştır. $\mathrm{Bu}$ durum alçının yapısı ile açıklanabilir. Üçlü karışımlarla üretilen kompozitlerin da az su emmeleri bu minerallerin kompozit içerisinde dolgu etkisi yapmasının sonucudur. Bu sayede boşluk oranı azaldığından su emme oranı azalmıştır.

\subsection{Ultrasonik Ses Geçirgenliği ve Isı İletim Katsayısı}

Ultra ses geçiş hızları ve isı iletim katsayıları Çizelge 5'de verilmiştir. Türk ve uluslararası standartlara göre bir malzemenin 1S1 yalıtım malzemesi olarak tanımlanması için onun sahip olduğu 1sı iletkenlik katsayısının $(\lambda)$ $0,1 \mathrm{~W} / \mathrm{mK}$ 'den küçük olması gerekir.

Çizelge 5. Ultra ses geçiş hızları ve isı iletim katsayıları

\begin{tabular}{|c|c|c|}
\hline Numuneler & $\begin{array}{c}\text { Ultra ses geçiş } \\
\text { hizlar1 } \\
(\mathrm{km} / \mathrm{s})\end{array}$ & $\begin{array}{c}\text { Is1 iletim } \\
\text { katsay1ları } \\
(\mathrm{w} / \mathrm{mK})\end{array}$ \\
\hline MA10 & 0,39 & 0,1061 \\
\hline MA20 & 0,31 & 0,1023 \\
\hline MAPO10 & 0,64 & 0,0194 \\
\hline MAPO20 & 0,61 & 0,0135 \\
\hline MPE10 & 0,65 & 0,0199 \\
\hline MPE20 & 0,62 & 0,0145 \\
\hline MV10 & 0,68 & 0,0205 \\
\hline MV20 & 0,66 & 0,0195 \\
\hline MZ10 & 0,63 & 0,0167 \\
\hline MZ20 & 0,69 & 0,0096 \\
\hline MPO10V10 & 0,75 & 0,0071 \\
\hline MPO20V20 & 0,72 & 0,0068 \\
\hline MPE10V10 & 0,75 & 0,0065 \\
\hline MPE20V20 & 0,71 & 0,0055 \\
\hline MPO10V10Z10 & 0,78 & 0,0051 \\
\hline MPO20V20Z20 & 0,79 & 0,0064 \\
\hline MPE10V10Z10 & 0,83 & 0,0068 \\
\hline MPE20V20Z20 & 0,86 & 0,0071 \\
\hline
\end{tabular}


Çizelge 5 incelendiğinde MA10 ve MA20 örneklerin dışında tamamı yalıtım malzemesi kabul edilebilir. Örneklerin mikro yapılarının bir biriyle ilişkili veya ilişkisiz birçok boşluk içermesi nedeniyle 1sı iletim katsayıları düşük bulunmuştur. Zira bu örneklerin ultrasonik ses geçiş hızları da bunu doğrulamaktadır. Çünkü söz konusu örneklerin ultrasonik ses geçiş hızları en küçük bulunmuştur. Bunun nedeni yine hem pomza hem de perlitin boşluklu yapısı ile açıklanabilir. Bu durum ise söz konusu ses dalgalarının yüzeyden geçerken absorbe edildiğinin bir sonucudur. Ayrıca, pomza, perlit, vermikülit ve zeolitin üçlü ve dörtlü karışımlarının ısı iletim katsayıları ile ultrasonik ses geçirgenlik değerleri ikili karışımlardan daha düşük bulunmuştur. Genellikle örneklerin birim hacim ağırlığı arttıkça malzemenin 1sı iletim katsayısının değeri de düşmektedir.

\subsection{Yangın Direnci}

\subsubsection{Kül Fırınında Yakma İşlemi}

Numuneler $50,100,150$ ve $200^{\circ} C^{\prime}$ de 30 dakika ısıl işlem gördükten sonra ağırlıklarına göre kütle kayıpları bulunmuştur. İkili katkılı numunelerin kütle kayıpları Şekil 2'de, üçlü karıșımların kütle kayıpları ise Şekil 3'de verilmiştir. İkili karışımlarla üretilen kompozitlerin yanma etkisiyle kütle kayıplarına göre, firın sıcaklığı arttıkça kütle kaybı da artmaktadır. Tüm örneklerde katkı oranı arttıkça kütle kaybı azalmaktadır.

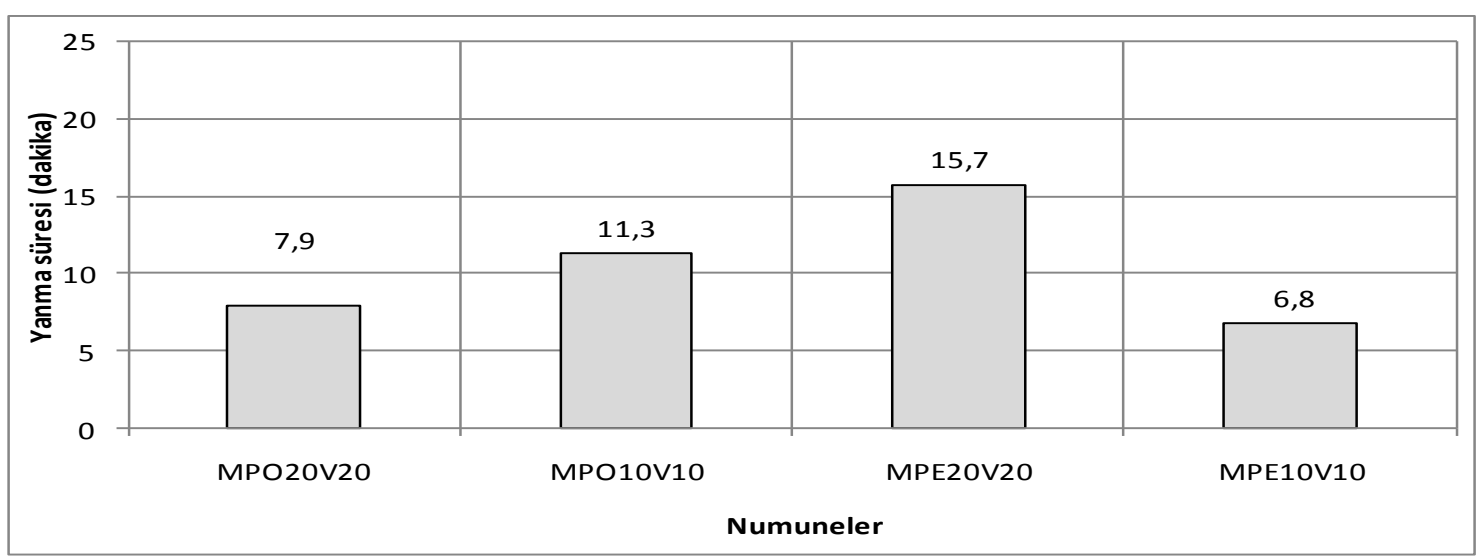

Şekil 2. İkili karışımların yakma sonrası kütle kayıplar

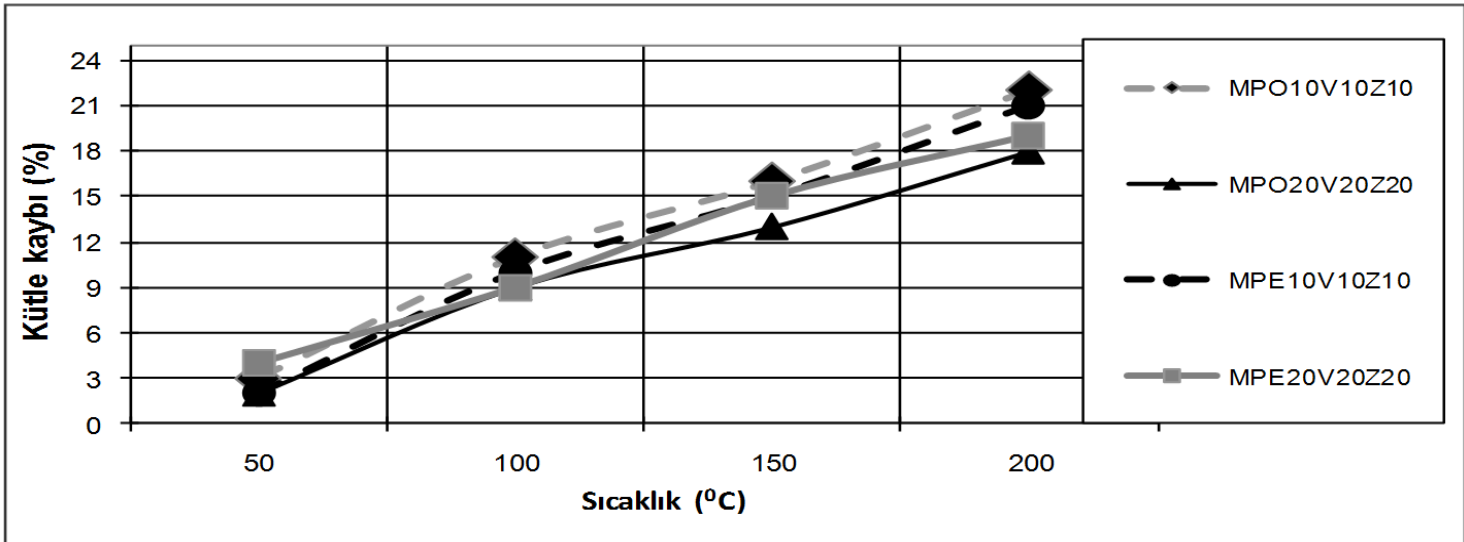

Şekil 3. Üçlü karışımların yakma sonrası kütle kayıpları 
Genel olarak alçı katkılı örneklerin tüm sıcaklıklarda elde edilen kütle kayıpları daha yüksek bulunmuştur. En düşük kütle kayıpları pomza katkılı örneklerde elde edilmiştir. Üçlü karışımlarla üretilen kompozitlerin yanma etkisiyle kütle kayıplarına göre, firın sıcaklığı arttıkça kütle kaybı da artmaktadır. Tüm örneklerde katkı oranı arttıkça kütle kaybı azalmaktadır.

Genel olarak üçlü karışımlarla elde edilen örneklerin tüm sicaklıklarda elde edilen kütle kayıpları daha düşük gözlenmiştir. Üçlü karışımların kütle kayıpları ikili katkılı örneklerinin kütle kayıplarının 50, 100, 150 ve $200^{\circ} \mathrm{C}$ sicakliklarda sirayla $\% 12,15,22$ ve $\% 25$ daha düşük bulunmuştur. Bunun nedeni daha sıkı yapıya sahip örneklerin yangına daha dirençli olması ile açıklanabilir.

\subsubsection{ASTM E 160-50’ye Göre Yangın Direnci}

İki mineral katkılı örneklerin tamamen yanma süreleri Şekil 4'de, üçlü mineral katkılı örneklerin yanma süreleri ise Şekil 5'de verilmiştir. Is1 transferinin sınırlı kalması hem aleve maruz kalan yüzey, hem de o yüzeyin yakın çevresindeki herhangi bir maddenin tutuşmaması açısından önemlidir [20]. İkili mineral katkılı kompozitlerin yanmaya karş1 en uzun dayanan örnek \%20 zeolit katkılı örnektir. Bu grupta en kısa sürede tamamen yanan örnek ise \%10 alçı katkılı MA10 örneğidir. Diğerlerinin $\% 20$ pomza $+\% 20$ perlit $\% 20$ zeolit katkılı örneğin yanmaya direnci en iyi bulunmuştur. $\mathrm{Bu}$ örneğin tamamen yanma süresi 15,7 dakika iken $\% 10$ pomza+\%10 perlit+\%10 vermikülit katkılı örneğin tamamen yanma süresi 6,8 dakika'dır. $\mathrm{Bu}$ sonuç zeolitin yanmaya karşı daha dirençli olduğunu göstermektedir. $\mathrm{Bu}$ sonuçlar önceki çalışmalarla [21] paralellik göstermektedir.

\section{SONUÇLAR}

Bu çalışmadan aşağıdaki sonuçlar elde edilmiştir.

1. Yanma deneyi sonuçlarına göre, en fazla ağırlı kaybı alçı katkılı örneklerde gerçekleşmiştir. Ağırlık kaybında en uygun sonucu pomza, perlit, vermikülit ve zeolit üçlü karışımlarla üretilen kompozitler vermiştir.

2. Yanmada oluşan ağırlık kayıpları ve yanma sıcaklık değerleri literatürde verilen sonuçlarla ve standartlarda belirtilen değerlerle uyumludur.

3. Çalışmada alçı, pomza, perlit vermikülit, zeolit katkılı numunelerin ikili karışımlarının ultra ses geçiş hızı ve 1sı iletim katsayısı daha düşük bulunmuştur.

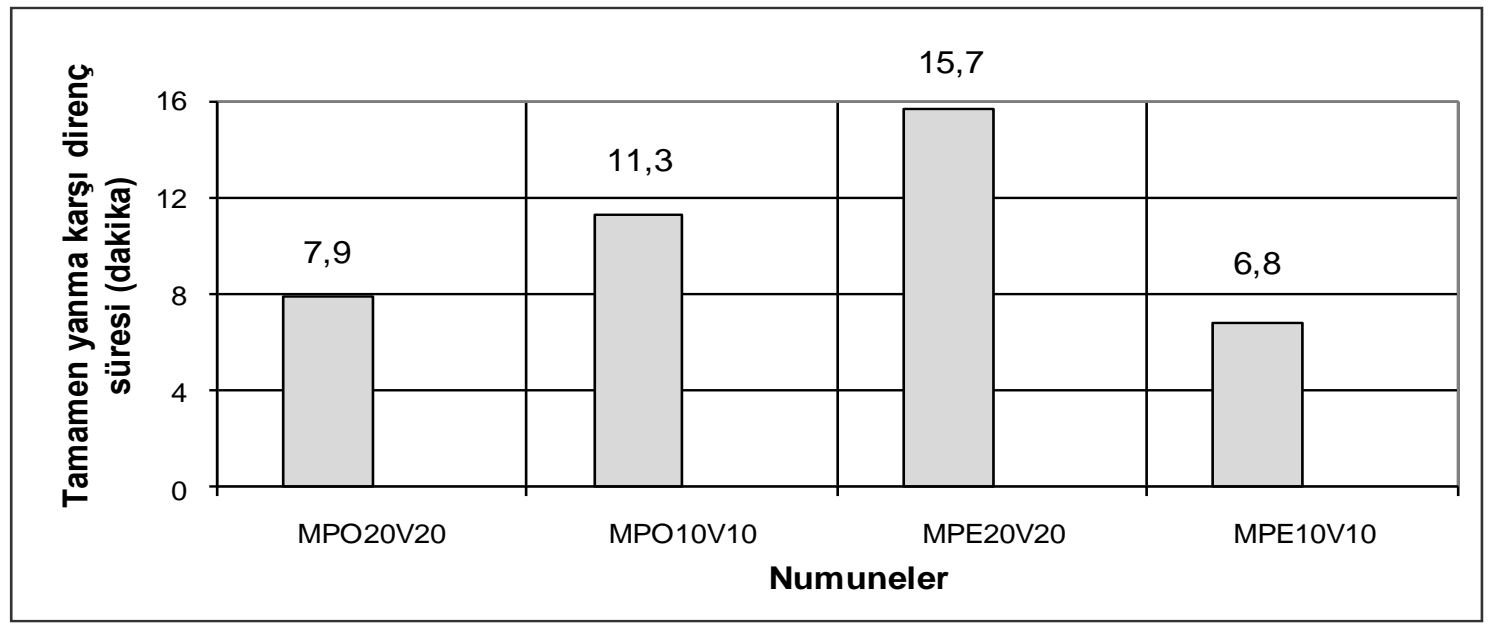

Şekil 4. İki mineral katkılı örneklerin tamamen yanma süreleri 


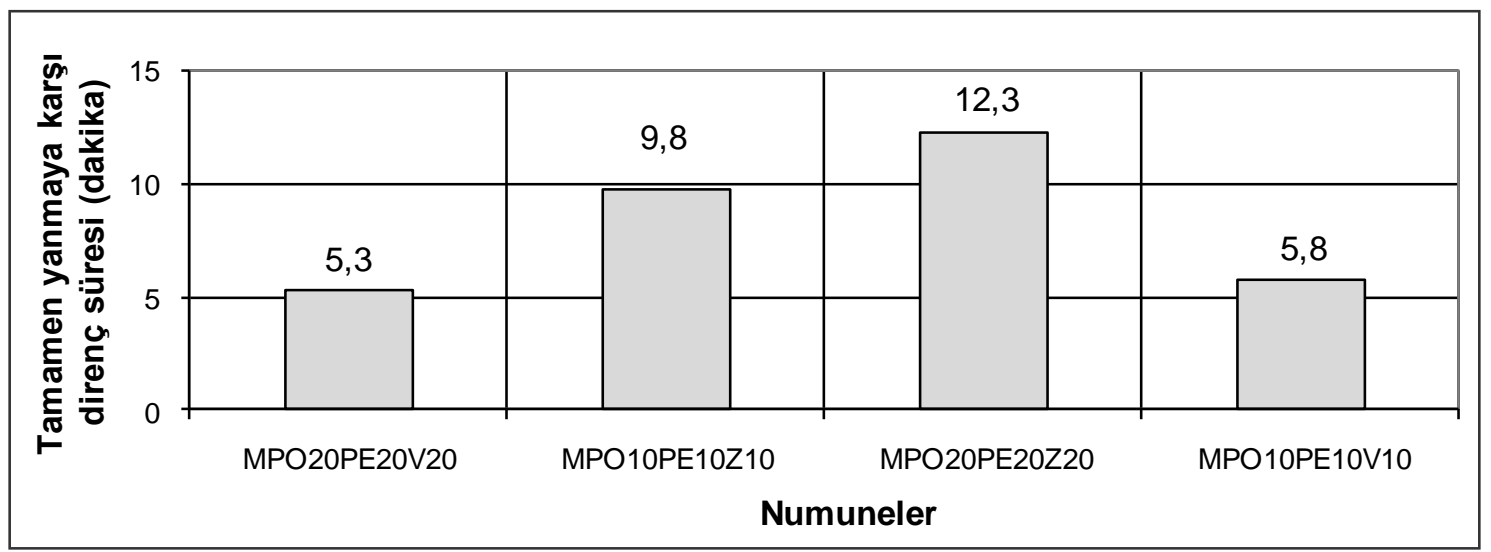

Şekil 5. Üçlü mineral katkılı örneklerin tamamen yanma süreler

4. Alçı, pomza, perlit vermikülit ve zeolitin üçlü karışımlarıyla üretilen kompozitlerin birim hacim ağırlıkları daha yüksek, ancak su emme oranları diğerlerine göre daha düşük bulunmuştur.

Bu çalışmada atık mukavva, alçı, pomza, perlit, vermikülit ve zeolit ile yangına dirençli bir kompozitler üretilmiştir. Elde edilen bu sonuçlara, denemeleri yapılan bu kompozitlerin yangın sırasında belirli sıcaklık etkisinin bulunduğu okul, bina, sanayi yapısı, firın, hamam vb. yapılarda söz konusu yalıtım malzemeleri kullanılabilir. $\mathrm{Bu}$ şekilde yapıların yangın dayanımı artırabilir.

\section{KAYNAKLAR}

1. Kanan N.O., 2014. Energy Efficiency Building Design and Fire Safety7th National Symposium on Roof and Facade 3-4 April 2014, Yildiz Technical University, 1515-1527, Besiktas- Istanbul .

2. Whitmore TC, Burslem D., 1997. Large-scale Disturbances in Tropical Rainforests. In: Newbery DM, Prins HHT, Brown ND (eds) Population and community dynamics in the tropics. Blackwell, Oxford, 13, 123-132.

3. Jacques G, Jean C, Jean-Claude M., 1997. Alternative Fire Resistance Strategies in Savanna Trees, Oecologia 110, 576-583.
4. Oymael S., Relationshıp of Water-Humidity and Fire Effects on Stability, Material Selection and Buildıng Design, www.imo.org.tr.

5. Bayraktar K.G.,2011. Tesisatlarda 1S1, ses ve yangın yalıtımı, 4. Ulusal tesisat mühendisliği kongresi ve sergisi, 665-676.

6. Temiz H, Kose M.M, Binici H.,2006. Effects of Fire on Precast Members: A Case Study, Engineering Failure Analysis 13, 1191-1201.

7. Liliana B. M, Exequiel S. R, Maria W, Analı'a V., 2006. Thermal Degradation and Fire Resistance of Unsaturated Polyester, Modified Acrylic Resins and their Composites with Natural Fibres, Polymer Degradation and Stability 91, 255-261.

8. Basdemir H, Demirel F., 2010. A Literature Review of Passive Fire Safety Precautions in Buildings, Journal of Polytechnic, 13, 101109 ,

9. Sainrat A., 2004. Fire Safety of Buildings Covered by the Construction Product Directive 89/106/EEC(CPD), EU MEDA Programme, Support to the Quality Infrastructure in Turkey, Bayındırlık ve Iskan Bakanlıg1, 0509.07.2004.

10. Eric M., 2011. Yapılarda Mimari Planlama ve Yapı Elemanları Açısından Yangın Sorunları, Yap1 Dergisi, 79, 41-43.

11. Gurdal E, Acun S., 2005. Is1 Yalitım Malzemeleri ve Yangın, İzolasyon Dünyası, 4, 48-52. 
12. Binici H, Kucukonder A, Eken M, Sevinc A.H, Tufenk N., 2013. Waste Paper and Cardboard Production Use of Insulation Material, Çukurova University Journal of the Faculty of Engineering and Architecture, 28, 21- 29.

13. Binici H, Aksogan O, Kaplan H, Gorur E.B, Bodur M.N., 2008. Performance of Ground Blast Furnace Slag (GBS) and Ground Basaltic Pumice (GBP) Concrete Against Seawater Attack, Construction and Building Materials 22, 1515-1526.

14. Erdem T.K., Meral C., Tokyay M., Erdogan T.Y., 2007. Use of Perlite as a Pozzolanic Addition in Producing Blended Cements, Cement and Concrete Composites, 29, 13-21.

15. Erdoğan B., 2005.Doğal ve Modifiye Doğal Zeolitlerde Etilen Adsorpsiyonu ve Bazı Uygulamalar, Yüksek Lisans Tezi, Fizik Anabilim Dalı, Fen Bilimleri Enstitüsü, AnadoluÜniversitesi.

16. Gülen J, Zorbay F, Arslan S., 2012. Zeolites and Usage Areas, Karaelmas Science and Engineering Journal, 2, 63-68.

17. Ozkırım I, Yorukogullari E., 2005. Characterisation ofBet Isotherm from Manisa, Gördes Natural Zeolite (clinoptilolite), D.P.U. Fen Bilimleri Enstitüsü, 9, 65-70.

18. Binici H, Temiz H, Sevinç AH, Eken M, Kucukonder A, Ergul T, 2013.Linear Absorption Coefficients of Mortar Samples Made with the Eggshell, Kahramanmaras Sütçü Imam University Journal of Engineering Sciences; 16, 11-17.

19. ASTM C 597(1994) Standart Test Method for Pulse Velocity Through Concrete, Annual Book of ASTM Standard.

20. EN 13501-2 Fire Classification of Construction Products and Building Elements-Part 2: Classification Using Data from Fire Resistance Tests, Excluding Ventilation Service, European Committe for Standardization, 2003.

21. Wang M, Wang X, Li L, Ji H., 2014.Fire Performance Od Playwood, BioResources, 9, 4934-4945. 